\title{
CYP27A1 expression is associated with risk of late lethal estrogen receptor-positive breast cancer in postmenopausal patients
}

\author{
Siker Kimbung ${ }^{1 *}$, Maria Inasu' ${ }^{1}$, Tor Stålhammar ${ }^{1}$, Björn Nodin², Karin Elebro ${ }^{1,3}$, Helga Tryggvadottir',
} Maria Ygland Rödström ${ }^{1}$, Karin Jirström ${ }^{2}$, Karolin Isaksson ${ }^{4,5}$, Helena Jernström ${ }^{1 \dagger}$ and Signe Borgquist ${ }^{1,6^{*}+}$

\begin{abstract}
Background: 27-Hydroxycholesterol (27HC) stimulates estrogen receptor-positive (ER+) breast cancer (BC) progression. Inhibiting the sterol 27-hydroxylase (CYP27A1) abrogates these growth-promoting effects of 27HC in mice. However, the significance of CYP27A1 expression on BC biology and prognosis is unclear.

Methods: Intratumoral CYP27A1 expression in invasive BC was measured by immunohistochemistry in two Swedish population-based cohorts ( $n=645$ and $n=813$, respectively). Cox proportional hazards models were used to evaluate the association between CYP27A1 expression and prognosis.

Results: CYP27A1 was highly expressed in less than 1/3 of the tumors. High CYP27A1 expression was more frequent among high-grade tumors lacking hormone receptor expression and with larger tumor sizes. Over a median of 12.2 years follow-up in cohort 1, high CYP27A1 expression was associated with impaired survival, specifically after 5 years from diagnosis among all patients [overall survival $(O S), H R_{\text {adjusted }}=1.93,95 \% \mathrm{Cl}=1.26-2.97$, $P=0.003$; breast cancer-specific survival (BCSS), $\left.\mathrm{HR}_{\text {adjusted }}=2.33,95 \% \mathrm{Cl}=1.28-4.23, P=0.006\right]$ and among patients $\geq 55$ years presenting with $E R+$ tumors $\left[O S, H R_{\text {adjusted }}=1.99,95 \% \mathrm{Cl}=1.24-3.21, P=0.004 ; B C S S, H R_{\text {adjusted }}=2.78\right.$, $95 \% \mathrm{Cl}=1.41-5.51, P=0.003]$.

Among all patients in cohort 2 (median follow-up of 7.0 years), CYP27A1 expression was significantly associated with shorter OS and RFS in univariable analyses across the full follow-up period. However after adjusting for tumor characteristics and treatments, the association with survival after 5 years from diagnosis was non-significant among all patients [OS, $\mathrm{HR}_{\text {adjusted }}=1.08,95 \% \mathrm{Cl}=0.05-2.35, P=0.83$ and $\left.\mathrm{RFS}, \mathrm{HR}_{\text {adjusted }}=1.22,95 \% \mathrm{Cl}=0.68-2.18, P=0.50\right]$ as well as among patients $\geq 55$ years presenting with $E R+$ tumors [OS, $H R_{\text {adjusted }}=0.4695 \% \mathrm{Cl}=0.11-1.98, P=0.30$ and RFS, $\left.\mathrm{HR}_{\text {adjusted }}=0.9795 \% \mathrm{Cl}=0.44-2.10, P=0.93\right]$.

Conclusion: CYP27A1 demonstrated great potentials as a biomarker of aggressive tumor biology and late lethal disease in postmenopausal patients with ER+ BC. Future studies should investigate if the benefits of prolonged endocrine therapy and cholesterol-lowering medication in BC are modified by CYP27A1 expression.
\end{abstract}

Keywords: Cholesterol, 27-hydroxycholesterol, CYP27A1, Breast cancer, Prognosis

\footnotetext{
*Correspondence: siker.kimbung@med.lu.se; signe.borgquist@auh.rm.dk

${ }^{\dagger}$ Helena Jernström and Signe Borgquist contributed equally to this work.

'Department of Clinical Sciences Lund, Division of Oncology, Lund

University, Barngatan 4, SE-221 85 Lund, Sweden

Full list of author information is available at the end of the article
}

(c) The Author(s). 2020 Open Access This article is licensed under a Creative Commons Attribution 4.0 International License, which permits use, sharing, adaptation, distribution and reproduction in any medium or format, as long as you give appropriate credit to the original author(s) and the source, provide a link to the Creative Commons licence, and indicate if changes were made. The images or other third party material in this article are included in the article's Creative Commons licence, unless indicated otherwise in a credit line to the material. If material is not included in the article's Creative Commons licence and your intended use is not permitted by statutory regulation or exceeds the permitted use, you will need to obtain permission directly from the copyright holder. To view a copy of this licence, visit http://creativecommons.org/licenses/by/4.0/. The Creative Commons Public Domain Dedication waiver (http://creativecommons.org/publicdomain/zero/1.0/) applies to the data made available in this article, unless otherwise stated in a credit line to the data. 


\section{Background}

Over $75 \%$ of primary breast cancers (BC) express the estrogen receptor $(\mathrm{ER})$ alpha $(\alpha)$ and depend on the ER signaling for sustained growth and survival $[1,2]$. Consequently, several targeted therapeutics interfering with ER signaling have been developed and initially are very successful in controlling the ER+ disease. However, a significant number of tumors become resistant to treatment and the patients present with disease recurrences both locally and at distant sites [2]. Metastasis is a principal cause of $\mathrm{BC}$-related death [3]. Importantly, $\mathrm{BC}$ is still the leading cause of cancer-related deaths among women worldwide [3]. Understanding the underlying factors promoting disease onset and progression and developing more precise biomarkers and effective therapeutic strategies for early prognostic decisionmaking and to overcome therapy resistance, remains a pertinent research priority.

Obesity and overweight have been shown to increase the risk of postmenopausal $\mathrm{ER}+\mathrm{BC}$ onset and progression by about 50\% [4-9]. High cholesterol, which is often associated with overweight/obesity, has also emerged as a risk factor for postmenopausal $\mathrm{BC}$ onset and progression [9-11]. Preclinical studies have demonstrated that high cholesterol favors cancer progression in mice [12-14], and molecular profiling studies have shown that cholesterol metabolism is often reprogrammed in many cancer types [15-19]. We and others have reported that the concomitant use of cholesterollowering medications during adjuvant therapy for $\mathrm{BC}$ is associated with improved survival outcomes, especially among postmenopausal patients with ER+ disease [2023]. Thus, a distinct role for cholesterol in promoting $\mathrm{BC}$ progression has emerged, strongly in favor for the prescription of therapeutics that interfere with cholesterol metabolism in the management of ER+ BC. However, the incomplete understanding of the biochemical mechanisms directly responsible for the pathogenicity of cholesterol in cancer has hindered the progress of this promising therapeutic strategy in the fight against BC.

Nelson and colleagues [12] have validated the previous in vitro data showing that the cholesterol metabolite 27hydroxycholesterol $(27 \mathrm{HC})$ is a potent ER $\alpha$ ligand [24, 25 ] and have extended these findings to clearly demonstrate that $27 \mathrm{HC}$ is capable of promoting $\mathrm{ER}+\mathrm{BC}$ progression in mice. Importantly, the ability of $27 \mathrm{HC}$ to stimulate the transcriptional activity of ER $\alpha$ leading to $\mathrm{BC}$ progression was highly dependent on the concentration of $17 \beta$-estradiol in the surroundings; $27 \mathrm{HC}$ mainly activated ER $\alpha$ in the absence of estrogen or under hypoestrogenic conditions while it principally displayed antagonistic effects on ER $\alpha$ under normal to high estrogenic conditions [24-26]. This estrogen-dependent property of $27 \mathrm{HC}$ on ER $\alpha$ activity qualifies it as the only characterized endogenously occurring selective estrogen receptor modulator (SERM) with a great potential to differentially impact ER+ BC progression and outcome depending on the patient menopausal status but this remains to be comprehensively investigated in clinical BC.

$27 \mathrm{HC}$ is synthesized from cholesterol by the sterol 27 hydroxylase (CYP27A1). Nelson et al. have further demonstrated that the tumor growth-enhancing effect of a high cholesterol diet in mice is attributable to $27 \mathrm{HC}$ and not directly to cholesterol since the pro-tumorigenic effects of $27 \mathrm{HC}$ and a high-cholesterol diet in the mice were abrogated by genetic and pharmacological inhibition of CYP27A1 [12, 27]. These novel results have increased the attention in targeting cholesterol metabolism in $\mathrm{BC}$ and have brought CYP27A1 into the repertoire of druggable targets for treating ER+ BC. Translating these interesting preclinical findings into effective treatments is still limited by, among other things, the absence of sensitive assays to measure $27 \mathrm{HC}$ levels in very small amounts of material such as the very scarce clinical tumor samples, specific targeted drugs and biomarkers for personalizing treatment. It is still unclear how $27 \mathrm{HC}$ levels in the tumormicroenvironment impact the course of $\mathrm{BC}$ progression and survival in patients. To uncover relevant associations between tumor pathological features, menopausal status, and $\mathrm{BC}$ prognosis in relation to intratumoral CYP27A1 expression, we performed immunohistochemistry to quantify CYP27A1 expression in two separate Swedish population-based prospective cohorts of patients with invasive primary $\mathrm{BC}$.

\section{Patients and methods Study populations Cohort 1: Malmö Diet and Cancer Study (MDCS)}

Initially, CYP27A1 expression was quantified in invasive breast tumors from women diagnosed with primary BC during follow-up in the prospective population-based cohort study: Malmö Diet and Cancer Study (MDCS). The MDCS prospectively enrolled 28,098 participants from the Malmö municipality, of which 17,035 were women, to study associations between diet and cancer. Recruitment of study participants was initiated in March 1991 and closed in September 1996. Detailed information regarding MDCS study design, inclusion and exclusion criteria, and data collection has been reported previously [28, 29]. From March 1991 through December 2010, 1016 women with incident BCs were identified through record linkage. Patient and tumor characteristics at the time of $\mathrm{BC}$ diagnosis were obtained from medical records and vital status are ascertained by record linkage with the Swedish Cancer Registry and the Southern Swedish Regional Tumor Registry [30, 31]. 


\section{Cohort 2: Breast Cancer-Blood (BC-Blood) study}

To validate and extend our findings, CYP27A1 expression was also assessed in an independent cohort of female patients diagnosed with primary $\mathrm{BC}$ at the Skåne University Hospital in Lund, BC-blood study. This prospective population-based cohort recruited patients between October 2002 and August 2019. All participants filled in an extensive questionnaire including reproductive and lifestyle factors and medication use, including statins. Body and weight measurements were collected by a research nurse at study inclusion prior to surgery and at each scheduled postoperative visit to complement standard clinical examination procedures. Other patient and tumor characteristics at time of $\mathrm{BC}$ diagnosis were obtained from medical records [32-34]. From study onset in October 2002 through June 2012, 1116 patients were included and a detailed description of the tumor and patient characteristics for this subset has been previously reported [35-38].

\section{Patient selection for the current analyses}

Herein, we focus on invasive primary BCs only; patients with ductal carcinoma in situ only, who received preoperative treatment, or who had a distant metastatic event or died $\leq 0.3$ years after diagnosis were excluded. Consequently, 910 and 987 patients with invasive primary $\mathrm{BC}$ remained in the MDCS and BC-blood cohorts, respectively, and were eligible for inclusion in our analyses. Archived formalin-fixed paraffin-embedded (FFPE) blocks were collected wherever possible, and tissue microarrays (TMAs) were constructed for each cohort (Fig. 1).

\section{Immunohistochemistry (IHC)}

TMAs including two $1 \mathrm{~mm}$ cores from representative regions of each tumor were constructed for each cohort. IHC staining and evaluation of CYP27A1 expression was performed as previously described [12, 39]. Briefly, $4 \mu \mathrm{m}$ sections were cut from FFPE TMA blocks, deparaffinized, treated with antigen retrieval buffer (citrate,

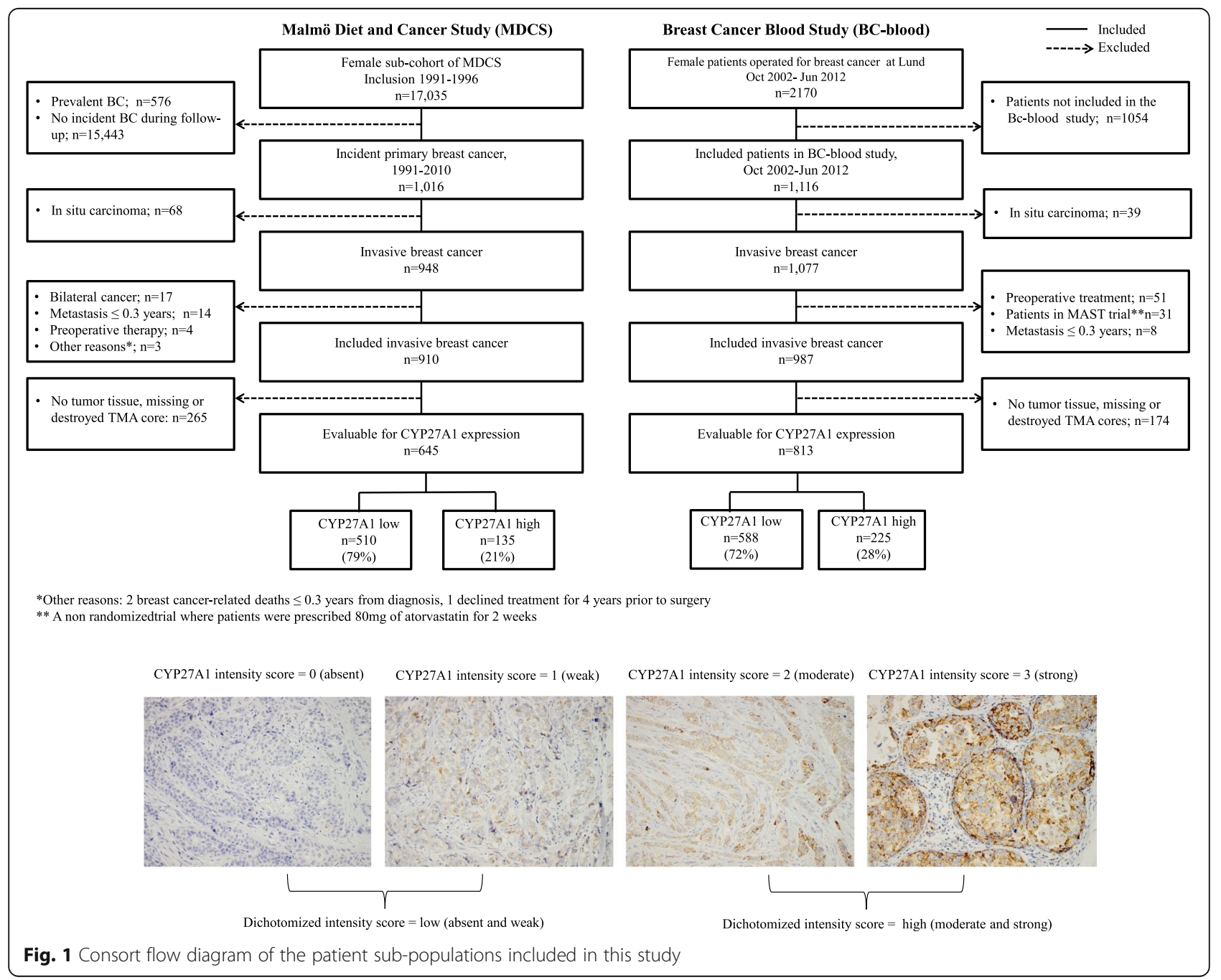


$\mathrm{pH}$ 6) for $20 \mathrm{~min}$, and then reacted with the antiCYP27A1 antibody for $2 \mathrm{~h}$ (ab126785, Abcam; 1:300 dilution). CYP27A1 expression was evaluated only in tumor cells, and a patient was considered to have a CYP27A1-positive tumor when a granular cytoplasmic reactivity was observed in at least $20 \%$ of tumor cells in all evaluable cores for that patient. Staining in stroma cells was not considered. A semi-quantitative intensity score, 0 (absent), 1 (weak), 2 (moderate), or 3 (strong), was adopted for annotating the staining intensities to further differentiate the results. Two investigators blinded to other pathological and survival data performed the IHC evaluation, with guidance from a pathologist. In cases of disagreement (MDCS 6\% and BCblood 9\%), a consensus score was established. For statistical analysis, the intensity scores were summarized into a dichotomized variable; low (absent and weak) and high (moderate and strong). Finally, due to no archival FFPE blocks, missing cores, non-intact or poor-quality cores, lack of tumor tissue in the core, and or low cellularity, CYP27A1 expression was successfully evaluated in $71 \%$ $(645 / 910)$ and $82 \%(813 / 987)$ of the eligible invasive primary tumors in MDCS and BC-blood, respectively (Fig. 1). The REMARK guidelines for biomarker assessment and reporting were respected in the analyses presented in this report [40].

\section{Endpoints}

The primary endpoint explored in this study was overall survival (OS), defined as time from $\mathrm{BC}$ diagnosis until death due to any cause. Other endpoints explored were breast cancer-specific survival (BCSS; defined as the time from $\mathrm{BC}$ diagnosis to death from a $\mathrm{BC}$-related cause only) and recurrence-free survival (RFS; defined as time from $\mathrm{BC}$ diagnosis until earliest occurrence of invasive locoregional recurrence, distant metastasis, or death from any cause).

\section{Statistical analyses}

The distribution of patient and tumor characteristics in relation to CYP27A1 expression are presented as percentages (categorical variables) or median and interquartile range (continuous variables). For MDCS power calculations including 600 patients, of which $20 \%$ had a high intratumoral expression of CYP27A1 and with a median survival time of 10 years for patients with low intratumoral CYP27A1 expression, it was possible to detect true HRs of $\leq 0.71$ or $\geq 1.36$ with a probability (power) of 0.8. Similarly, for BC-blood study power calculations including 800 patients, of which $25 \%$ had a high intratumoral expression of CYP27A1 and with a median survival time of 7 years for patients with low intratumoral CYP27A1 expression, it was possible to detect true HRs of $\leq 0.75$ or $\geq 1.38$ with a probability (power) of 0.8 . The type I error probability associated with this test of the null hypothesis that the experimental and control survival curves are equal is 0.05. The power calculations were performed with the PS Power and Sample Size Calculation Program, version 3.1.2 [41].

Unexpectedly, shorter storage duration of FFPE block, calculated as the time between surgery and IHC staining for CYP27A1, was statistically significantly associated with high CYP27A1 expression intensity in both cohorts (Table 1). Hence, all associations between CYP27A1 expression and tumor-pathological and patient characteristics reported in this study have been adjusted for the FFPE block storage duration (continuous variable) using logistic regression and Cox regression models, respectively. The impact of CYP27A1 expression is presented as odds ratios (OR) or hazard ratios (HR) and 95\% confidence intervals (CI) where applicable. Multivariable models were adjusted for age at diagnosis (age $<55$ years vs age $\geq 55$ years), tumor size $>20 \mathrm{~mm}$ (yes/no), axillary lymph node involvement (yes/no), histological grade (III vs. I and II), ER status ( $\leq 10 \%$ vs $>10 \%)$, adjuvant breast cancer therapy [radiotherapy (yes/no), chemotherapy (yes/no), and endocrine therapy (yes/no)], and storage time of FFPE block (continuous). No statistically significant evidence for non-proportional hazards was found in univariate Cox regression models for any of the endpoints assessed $(P>0.05$ for all proportional hazard tests). Of note, we used the cut-off of 55 years for dichotomizing patient age to serve as a proxy for postmenopausal status in this study since menopausal status was not precisely assessed at the time of primary $\mathrm{BC}$ diagnosis. All statistical tests were two-sided, and $P<0.05$ was considered to be statistically significant. All analyses presented in this study are exploratory and are not adjusted for multiple testing.

\section{Results}

Similarities and differences in patient and tumor characteristics at baseline between the two cohorts

The distributions of patients, tumor characteristics, and adjuvant treatment were compared between the overall populations and the subsets of patients with evaluable CYP27A1 expression within each cohort and were found to be well-balanced (Supplementary Table 1) for the majority of factors assessed. However, important differences in patient and tumor characteristics and treatment history were noted between the cohorts. The median age at diagnosis was higher in MDCS (65.1 years; IQR $=60.2$ 71.9 years) compared to BC-blood (60.9 years; IQR = 52.4-68.1 years). An overwhelming majority (90.2\%) of the patients in MDCS were 55 years and older (presumably postmenopausal) compared to $68.8 \%$ in BC-blood. Although the proportion of patients with ER+ tumors was similar between the two cohorts (87\%), endocrine 
Table 1 Baseline tumor and patient characteristics in relation to CYP27A1 expression

\begin{tabular}{|c|c|c|c|c|c|c|}
\hline & \multicolumn{3}{|l|}{ MDCS } & \multicolumn{3}{|l|}{ BC-blood } \\
\hline & CYP27A1 low & CYP27A1 high & $\mathrm{OR} *(95 \% \mathrm{Cl})$ & CYP27A1 low & CYP27A1 high & $\mathrm{OR}^{*}(95 \% \mathrm{Cl})$ \\
\hline \multirow[t]{2}{*}{ Characteristic } & $N(\%)$ & $N(\%)$ & & $N(\%)$ & $N(\%)$ & \\
\hline & $510(79.1)$ & $135(20.9)$ & & $588(72.3)$ & $225(27.7)$ & \\
\hline Age at $B C$ diagnosis & $64.9(60.1-71.1)^{a}$ & $66.2(60.4-73.5)^{\mathrm{a}}$ & $1.02(0.99-1.05)$ & $60.7(52.4-67.8)^{a}$ & $61.3(52.3-69.2)^{\mathrm{a}}$ & $1.00(0.98-1.01)$ \\
\hline Age at diagnosis $<55$ yrs & $53(10)$ & $10(7.4)$ & ref & 179 (30.4) & $74(32.9)$ & ref \\
\hline Age at diagnosis $\geq 55$ yrs & $457(90)$ & $125(92.6)$ & $0.94(0.44-2.00)$ & 409 (69.6) & $151(67.1)$ & $0.84(0.60-1.18)$ \\
\hline \multicolumn{7}{|l|}{ Estrogen receptor status } \\
\hline Positive & $428(89.7)$ & $94(78.3)$ & ref & $545(92.7)$ & $166(74.1)$ & ref \\
\hline Negative & $49(10.3)$ & $26(12.6)$ & $2.52(1.50-4.20)$ & $43(7.3)$ & $58(25.9)$ & $4.75(3.05-7.41)$ \\
\hline \multicolumn{7}{|l|}{ Progesterone receptor status } \\
\hline Positive & $243(56.4)$ & $52(47.3)$ & ref & $445(75.7)$ & $135(60.3)$ & ref \\
\hline Negative & $188(43.6)$ & $58(52.7)$ & $1.81(1.16-2.84)$ & $143(24.3)$ & $89(39.7)$ & $2.17(1.55-3.03)$ \\
\hline \multicolumn{7}{|l|}{ Tumor size } \\
\hline$\leq 20 \mathrm{~mm}$ & $353(69.6)$ & $92(68.1)$ & ref & $446(75.9)$ & $150(66.7)$ & ref \\
\hline$>20 \mathrm{~mm}$ & $154(30.4)$ & $43(31.9)$ & $1.10(0.73-1.70)$ & $142(24.1)$ & 75 (33.3) & $1.62(1.15-2.27)$ \\
\hline \multicolumn{7}{|l|}{ Nodal status } \\
\hline Negative & $304(63.3)$ & $90(68.7)$ & ref & $351(59.8)$ & $144(64.3)$ & ref \\
\hline Positive & $176(36.7)$ & $41(31.3)$ & $0.81(0.54-1.23)$ & $236(40.2)$ & $80(35.7)$ & $0.84(0.61-1.16)$ \\
\hline \multicolumn{7}{|l|}{ Nottingham histological grade } \\
\hline I and II & 369 (73.9) & $82(62.6)$ & ref & $466(79.3)$ & $134(59.6)$ & ref \\
\hline III & $130(26.1)$ & $49(37.4)$ & $1.70(1.13-2.60)$ & $122(20.7)$ & $91(40.4)$ & $2.37(1.69-3.32)$ \\
\hline FFPE block storage time, yrs & $15.0(12.0-19.0)^{\mathrm{a}}$ & $13.0(10.0-17.0)^{a}$ & $0.93(0.89-0.97)$ & $10.0(7.0-12.0)^{a}$ & $8.0(6.0-11.0)^{a}$ & $0.87(0.82-0.92)$ \\
\hline \multicolumn{7}{|l|}{ Radiotherapy } \\
\hline No & $160(34.3)$ & $55(44.4)$ & ref & $214(36.4)$ & $78(34.7)$ & ref \\
\hline Yes & $307(65.7)$ & $69(55.6)$ & $0.65(0.43-0.97)$ & $374(63.6)$ & $147(65.3)$ & $1.06(0.76-1.47)$ \\
\hline \multicolumn{7}{|l|}{ Endocrine therapy } \\
\hline No & $204(40.6)$ & $50(37.9)$ & ref & $158(26.9)$ & $84(37.3)$ & ref \\
\hline Yes & $298(59.4)$ & $82(62.1)$ & $0.93(0.61-1.40)$ & $429(73.1)$ & $140(62.5)$ & $0.62(0.45-0.87)$ \\
\hline \multicolumn{7}{|l|}{ Chemotherapy } \\
\hline No & 388 (82.9) & 97 (78.9) & ref & 457 (77.7) & $149(66.2)$ & ref \\
\hline Yes & $80(17.1)$ & $26(21.1)$ & $1.23(0.74-2.03)$ & $131(22.3)$ & 76 (33.8) & $1.51(1.07-2.14)$ \\
\hline
\end{tabular}

${ }^{a}$ Median (IQR), OR odds ratio, ref reference category, FFPE formalin-fixed paraffin-embedded, yrs years. Bold numbers indicate statistically significant comparisons *Odds ratios are only adjusted for storage time of FFPE blocks

therapy and chemotherapy were more generously used in BC-blood (70.2\% and $25.5 \%$, respectively) compared to those in MDCS (59.9\% and $17.9 \%$, respectively). Further, the proportion of tumors lacking progesterone receptor (PgR) expression was higher in MDCS (45.5\%) compared to that in BC-blood (28.6\%).

\section{CYP27A1 expression in relation to tumor and patient characteristics}

The distribution of tumor characteristics in relation to CYP27A1 expression is presented in Table 1. High CYP27A1 expression was observed in about $21 \%$ and $28 \%$ of tumors in MDCS and BC-blood, respectively (Table 1).
In both cohorts, high CYP27A1 tumors were more likely to lack hormone receptor (ER and $\mathrm{PgR}$ ) expression and to have Nottingham histological grade III $(P<0.05$ for all comparisons). In BC-blood, high CYP27A1 expression was also significantly associated with larger tumor size $(P=$ 0.02 ) and patients with high CYP27A1 tumors were more likely to have received chemotherapy $(\mathrm{OR}=1.51,95 \% \mathrm{CI}=$ 1.07-2.14) and less likely to have received endocrine treatment $(\mathrm{OR}=0.62,95 \% \mathrm{CI}=0.45-0.87)$. In MDCS, radiotherapy treatment was less frequent among patients with high CYP27A1 tumors $(\mathrm{OR}=0.65,95 \% \mathrm{CI}=0.43-0.97)$.

In the BC-blood study, where preoperative weight, height, and waist and hip circumferences were 
measured, there were no statistically significant associations between high CYP27A1 expression and body mass index $\geq 25 \mathrm{~kg} / \mathrm{m}^{2}$ or waist-to-hip ratio $>0.85$ (both $P>$ 0.05 , Supplementary Table 2). Similarly, there was no association between self-reported preoperative statin use and CYP27A1 expression in the BC-blood study $(P=$ 0.45). Similarly, in MDCS, there was no association between CYP27A1 expression and history of statin use according to data retrieved from the Swedish Prescribed Drug Register and Swedish Death Registry $(P=0.24)$.

\section{CYP27A1 expression and long-term prognosis in the MDCS cohort}

The significance of CYP27A1 expression in relation to survival was first explored among all eligible patients, followed by pre-specified sub-analyses stratified by age at diagnosis (age $<55$ years vs age $\geq 55$ years) and ER expression $(\leq 10 \%$ vs $>10 \%)$. OS and BCSS were the primary and secondary endpoints, respectively. At the end of follow-up (December 31, 2016), 221 deaths had been registered among the 645 patients eligible for inclusion in survival analyses and approximately half of the deaths $(n=112)$ had BC as an underlying cause. The median follow-up for all patients was 10.8 years (IQR; 7.4-15.2 years) and 12.2 years (IQR; 9.1-16.6 years) for patients who were alive and still at risk at data cut-point.

High CYP27A1 expression was associated with poorer OS and BCSS, specifically impacting the period after 5 years from primary diagnosis (Fig. 2a, b). In Cox regression analyses adjusted for FFPE block storage

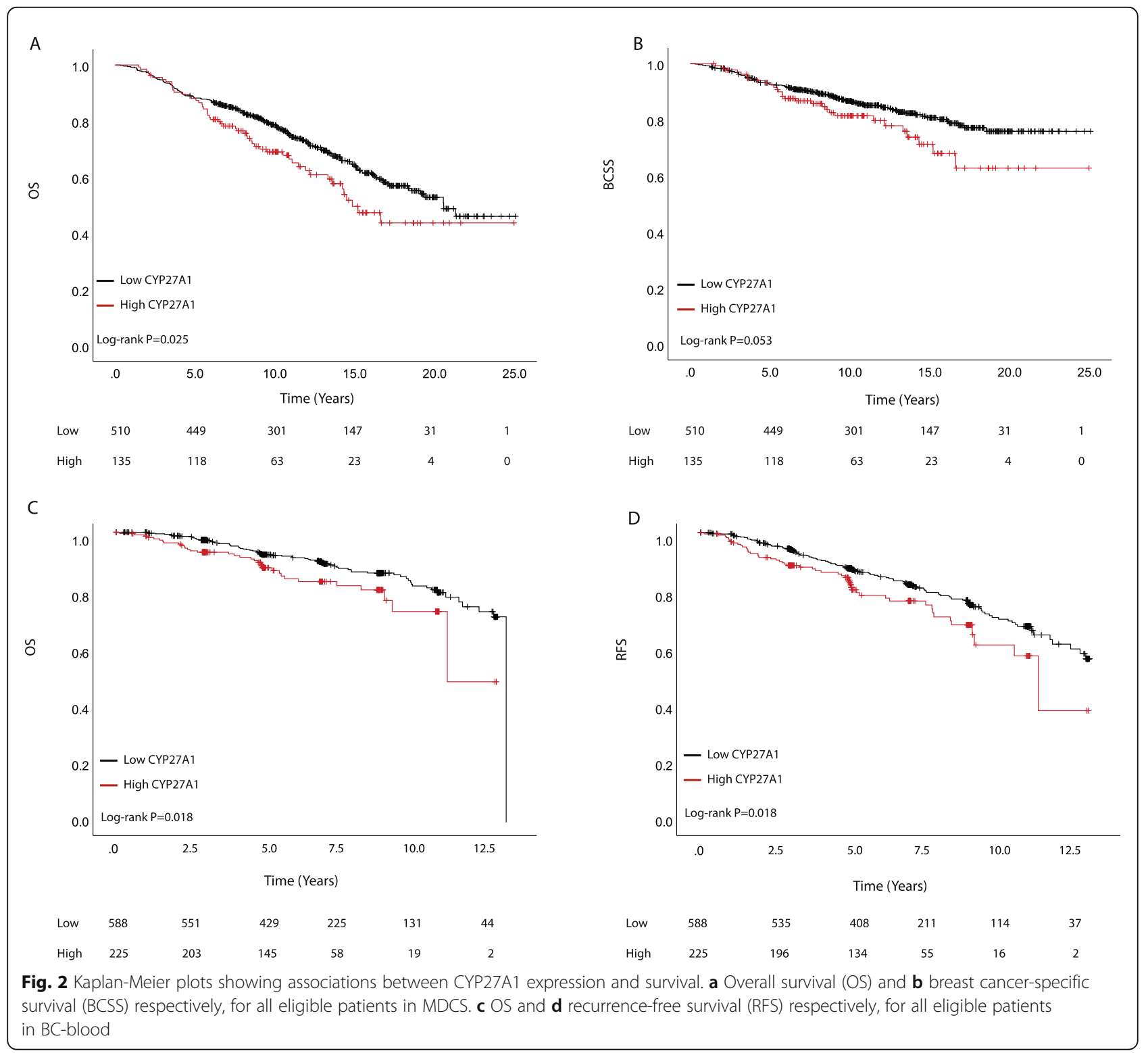


duration only and including all eligible patients, both OS and BCSS were statistically significantly worse for patients with high CYP27A1 tumors [OS; $\mathrm{HR}=1.38$, $95 \% \mathrm{CI}=1.01-1.89, \quad P=0.04$ and BCSS; $\mathrm{HR}=1.60$, $95 \% \mathrm{CI}=1.01-2.39, P=0.04$; respectively]. Similar trends were obtained in sub-analyses among all patients with $\mathrm{ER}+$ tumors $[\mathrm{OS} ; \mathrm{HR}=1.50,95 \% \mathrm{CI}=1.04-2.20, P=0.03$ and $\mathrm{BCSS} ; \mathrm{HR}=1.53,95 \% \mathrm{CI}=0.89-2.63, P=0.12$; respectively]. In fully adjusted multivariable Cox models covering the entire follow-up period, CYP27A1 emerged as an independent high-risk factor, increasing the average risk for all-cause mortality by $40 \%$ for all patients and by $60 \%$ for all ER+ patients and also for women older than 55 years of age with ER+ disease. Likewise, the average risk of dying specifically due to a $\mathrm{BC}$-related cause remained elevated by about $40 \%$ for all patients and between 60 and $70 \%$ for ER+ patients with high CYP27A1 compared to low CYP27A1 tumors, although the evidence was weaker statistically (Supplementary Table 3).

Postmenopausal patients presenting with ER+ primary breast tumors are recommended 5 years of endocrine therapy as the backbone of their adjuvant cancer treatment regimen, and currently extended adjuvant therapy is suggestively discussed with the patient [42]. The separation of the survival curves at 5 years seen in the previous analyses is therefore remarkable because it coincides with the important milestone for patients with $\mathrm{ER}+\mathrm{BCs}$ when adjuvant cancer treatment often ends. We therefore performed a 5-year landmark multivariable Cox analysis to specifically compare the risks of an event before and after 5 years from BC diagnosis by CYP27A1 expression. Interestingly, no statistically significant differences in the risks for an OS or BCSS event were found for the first 5 years as expected, but the risks for an OS event increased above $75 \%$, while the risks for BCSS events more than doubled for patients with high CYP27A1 tumors (Table 2). Importantly, CYP27A1 was the only independent factor for both OS and BCSS in the fully adjusted multivariable models (model 2) including patients with $\mathrm{ER}+$ disease and patients aged $\geq 55$ years presenting with ER+ tumors only.

In analogy, CYP27A1 expression did not impact ERnegative $\mathrm{BC}$ prognosis, but the analysis was underpowered due to few cases $(N=75$, data not shown). Similarly, due to too few cases $(N=65)$, a meaningful assessment of the prognostic impact of CYP27A1 could not be performed in the age group $<55$ years.

\section{CYP27A1 expression and long-term prognosis in the BC- blood cohort}

To validate and extend our findings from MDCS, CYP27A1 expression in relation to OS and disease progression (RFS) were examined in the $\mathrm{BC}$-blood cohort.
At data cut-point (June 30, 2016), 108 OS events and 175 RFS events had been recorded among the 813 patients with valid CYP27A1 expression data. The median follow-up for all patients was 7.0 years (IQR; 4.2-9.1 years) and 7.0 years (IQR; 5.0-9.1 years) for patients who were alive and still at risk at data cut-point.

In the general population across the full follow-up period, both RFS and OS were significantly worse for patients with high CYP27A1 compared to low CYP27A1 tumors [RFS: $\mathrm{HR}=1.58,95 \% \mathrm{CI}=1.13-2.21, \quad P=0.008$ and $\mathrm{OS}: \mathrm{HR}=1.73,95 \% \mathrm{CI}=1.14-2.64, P=0.011]$ in Cox regression analyses adjusted for FFPE storage duration. Comparable results were obtained in KaplanMeier analyses shown in Fig. 2c, d. An analogous nonsignificant trend towards poorer survival for patients with high CYP27A1 tumors was observed among patients with ER+ tumors [RFS: $\mathrm{HR}=1.34,95 \% \mathrm{CI}=0.89$ 2.01, $P=0.16$; and OS: $\mathrm{HR}=1.47,95 \% \mathrm{CI}=0.86-2.49$, $\mathrm{P}=0.16$, respectively]. Also, CYP27A1 expression was not significantly associated with prognosis among women aged $\geq 55$ years presenting with ER+ tumors [RFS: $\mathrm{HR}=1.10,95 \% \mathrm{CI}=0.67-1.80, P=0.70$; OS: $\mathrm{HR}=$ $1.28,95 \% \mathrm{CI}=0.70-2.36, P=0.42$, respectively]. Notably, among younger patients $<55$ years (presumably pre- and perimenopausal) presenting with ER+ tumors, overexpression of CYP27A1 was associated with over twofold increased risk of recurrence [RFS, $\mathrm{HR}=2.19,95 \% \mathrm{CI}=$ 1.05-4.59, $P=0.04]$ and death $[\mathrm{OS}, \mathrm{HR}=3.27,95 \% \mathrm{CI}=$ 0.99-10.79, $P=0.05]$. CYP27A1 expression did not impact ER-negative breast cancer prognosis (data not shown). Adjusted HRs for OS and RFS for the full follow-up are presented in Supplementary Table 4. Though showing similar trends, CYP27A1 was not an independent prognostic factor in any of the multivariable models and patient subgroups. Furthermore, the risk estimates remained essentially the same after further adjustments for body mass index, waist-to-hip ratio, or preoperative statin use (data not shown).

The association between CYP27A1 expression and survival was also investigated in BC-blood using 5-year landmark multivariable Cox analyses (Table 3). No statistically significant difference in OS was observed for any of the Cox models or time periods. RFS event rates were, however, found to be more than three-folds significantly higher in patients $<55$ years presenting with $\mathrm{ER}+$ tumors during the first 5 years after $\mathrm{BC}$ diagnosis only. RFS differences were statistically non-significant for all other analyses.

\section{Discussion}

We evaluated the significance of CYP27A1 expression in invasive $\mathrm{BC}$ among patients from two independent population-based cohort studies in Southern Sweden. Intratumoral CYP27A1 expression was associated with 
Table 2 Adjusted hazard ratios (95\%Cl) for overall survival and breast cancer-specific survival by tumor CYP27A1 expression in MDCS cohort

\begin{tabular}{|c|c|c|c|c|c|c|c|c|}
\hline \multicolumn{3}{|c|}{ Model $0^{a}$} & \multicolumn{3}{|c|}{ Model $1^{b}$} & \multicolumn{3}{|c|}{ Model $2^{c}$} \\
\hline Cases & Events & $\begin{array}{l}\text { CYP27A1 high vs low } \\
\text { HR }(95 \% \mathrm{Cl})\end{array}$ & Cases & Events & $\begin{array}{l}\text { CYP27A1 high vs low } \\
\text { HR }(95 \% \mathrm{Cl})\end{array}$ & Cases & Events & $\begin{array}{l}\text { CYP27A1 high vs low } \\
\text { HR }(95 \% \mathrm{Cl})\end{array}$ \\
\hline
\end{tabular}

Follow-up period $\leq \mathbf{5}$ years

Overall survival

\begin{tabular}{|c|c|c|c|}
\hline \multirow[t]{2}{*}{ All } & \multirow[t]{2}{*}{645} & \multirow[t]{2}{*}{76} & $0.97(0.56-1.69)$ \\
\hline & & & $P=0.92$ \\
\hline \multirow[t]{2}{*}{ ER+ } & \multirow[t]{2}{*}{522} & \multirow[t]{2}{*}{52} & $1.05(0.53-1.03)$ \\
\hline & & & $P=0.87$ \\
\hline \multirow{2}{*}{$\begin{array}{l}\text { ER+ and age } \\
\geq 55 \text { yrs }\end{array}$} & \multirow[t]{2}{*}{472} & \multirow[t]{2}{*}{51} & $1.10(0.55-2.21)$ \\
\hline & & & $P=0.78$ \\
\hline
\end{tabular}

Breast cancer-specific survival

\begin{tabular}{|c|c|c|c|c|c|c|c|c|c|}
\hline \multirow{2}{*}{ All } & 645 & 46 & $0.92(0.44-1.93)$ & 569 & 41 & $0.67(0.30-1.51)$ & 514 & 38 & $0.54(0.22-1.31)$ \\
\hline & & & $P=0.83$ & & & $P=0.34$ & & & $P=0.17$ \\
\hline \multirow[t]{2}{*}{ ER+ } & 522 & 26 & $0.61(0.18-2.03)$ & 498 & 26 & $0.63(0.19-2.10)$ & 448 & 25 & $0.57(0.16-1.95)$ \\
\hline & & & $P=0.42$ & & & $P=0.45$ & & & $P=0.37$ \\
\hline \multirow{2}{*}{$\begin{array}{l}\text { ER+ and age } \\
\geq 55 \text { yrs }\end{array}$} & 472 & 25 & $0.64(0.19-2.16)$ & 450 & 25 & $0.64(0.19-2.14)$ & 400 & 24 & $0.63(0.18-2.15)$ \\
\hline & & & $P=0.47$ & & & $P=0.47$ & & & $P=0.46$ \\
\hline
\end{tabular}

Follow-up period $>5$ years

Overall survival

$\begin{array}{lccl}\text { All } & 567 & 145 & 1.66(1.14-2.43) \\ & & & P=0.009 \\ \text { ER+ } & 468 & 122 & \begin{array}{l}1.76(1.14-2.71) \\ P\end{array} \\ & & & =0.01 \\ \text { ER+ and } & 419 & 112 & 1.85(1.18-2.91) \\ \text { age } \geq \text { 55 yrs } & & & P=0.007\end{array}$

Breast cancer-specific survival

\begin{tabular}{|c|c|c|c|c|c|c|c|c|c|}
\hline \multirow[t]{2}{*}{ All } & 567 & 66 & $2.18(1.28-3.73)$ & 498 & 60 & $2.25(1.26-4.01)$ & 449 & 58 & $2.33(1.28-4.23)$ \\
\hline & & & $P=0.004$ & & & $P=0.006$ & & & $P=0.006$ \\
\hline \multirow[t]{2}{*}{ ER+ } & 468 & 54 & $2.22(1.19-4.12)$ & 445 & 54 & $2.18(1.18-4.03)$ & 399 & 52 & $2.26(1.20-4.27)$ \\
\hline & & & $P=0.01$ & & & $P=0.01$ & & & $P=0.01$ \\
\hline \multirow{2}{*}{$\begin{array}{l}\text { ER+ and age } \\
\geq 55 \mathrm{yrs}\end{array}$} & 419 & 46 & $2.56(1.33-4.91)$ & 398 & 46 & $2.57(1.34-4.94)$ & 352 & 44 & $2.78(1.41-5.51)$ \\
\hline & & & $P=0.005$ & & & $P=0.005$ & & & $P=0.003$ \\
\hline
\end{tabular}

$H R$ hazard ratio, $\mathrm{Cl}$ confidence interval, $E R+$ estrogen receptor positive

${ }^{a}$ Model 0: adjusted for FFPE block storage duration

${ }^{b}$ Model 1: adjusted for age at diagnosis, tumor size, lymph node involvement, ER expression, tumor histological grade and FFPE block storage duration

${ }^{c}$ Model 2: Model $1+$ adjusted for local (radiotherapy) and systemic (endocrine and chemotherapy) treatments

unfavorable tumor characteristics and significantly impaired survival with differential effects observed between the time periods $0-5$ years and greater than 5 years after diagnosis based on menopausal status. After adjusting for potential confounders, the risk for lethal disease among patients with high CYP27A1 tumors remained very significantly elevated in the MDCS cohort for all endpoints and subgroups, especially among older patients $\geq 55$ years presenting with $\mathrm{ER}+\mathrm{BC}$, distinctively impairing survival only after 5 years from primary tumor diagnosis.

In the recent past, a distinct role for cholesterol in promoting ER+ BC progression has emerged in preclinical studies, unraveling the promising connections between 27HC, CYP27A1, and ER+ breast cancer progression. In this study, tumor-specific CYP27A1 expression was used as a surrogate for intratumoral $27 \mathrm{HC}$ levels to investigate the impact on tumor biology and 
Table 3 Adjusted hazard ratios $(95 \% \mathrm{Cl})$ for overall survival and recurrence-free survival by tumor CYP27A1 expression in BC-blood cohort

\begin{tabular}{|c|c|c|c|c|c|c|c|c|}
\hline \multicolumn{3}{|c|}{ Model $0^{\mathrm{a}}$} & \multicolumn{3}{|c|}{ Model $1^{b}$} & \multicolumn{3}{|c|}{ Model $2^{c}$} \\
\hline Cases & Events & $\begin{array}{l}\text { CYP27A1 high vs low } \\
\text { HR }(95 \% \mathrm{Cl})\end{array}$ & Cases & Events & $\begin{array}{l}\text { CYP27A1 high vs low } \\
\text { HR }(95 \% \mathrm{Cl})\end{array}$ & Cases & Events & $\begin{array}{l}\text { CYP27A1 high vs low } \\
\text { HR }(95 \% \mathrm{Cl})^{\mathrm{b}}\end{array}$ \\
\hline
\end{tabular}

\section{Follow-up period $\leq 5$ years}

\section{Overall survival}

$\begin{array}{llll}\text { All } & 808 & 61 & 1.90(1.12-3.23) \\ & & & P=0.02 \\ \text { ER+ } & 697 & 41 & 1.84(0.93-3.62) \\ & & & P=0.07 \\ & & & 1.75(0.84-3.63) \\ \text { ER+ and age } & 486 & 37 & P=0.13 \\ \geq 55 \text { yrs } & & & 4.21(0.56-31.78) \\ \text { ER+ and age } & 208 & 4 & P=0.16\end{array}$

\section{Recurrence-free survival}

$\begin{array}{lccl}\text { All } & 808 & 99 & 1.76(1.15-2.71) \\ & & & P=0.01 \\ \text { ER+ } & 704 & 72 & 1.50(0.87-2.60) \\ & & & P=0.14 \\ & & & 1.12(0.58-2.17) \\ \text { ER+ and age } & 490 & 54 & P=0.73 \\ \geq 55 \text { yrs } & & & 3.25(1.20-8.76) \\ \text { ER+ and age } & 214 & 18 & P=0.02 \\ <55 \text { yrs } & & & \end{array}$

\section{Follow-up period $>5$ years}

\section{Overall survival}

$\begin{array}{llll}\text { All } & 570 & 47 & 1.50(0.72-2.93) \\ & & & P=0.29 \\ \text { ER+ } & 509 & 40 & 0.96(0.39-2.35) \\ & & & P=0.93 \\ & & & 1.46(0.43-4.92) \\ \text { ER+ and age } & 348 & 31 & P=0.54 \\ \begin{array}{l}\text { 555 yrs } \\ \text { ER+ and age }\end{array} & 124 & 9 & 0.38(0.08-1.70) \\ <55 \text { yrs } & & & P=0.41\end{array}$

\section{Recurrence-free survival}

\begin{tabular}{|c|c|c|c|}
\hline \multirow[t]{2}{*}{ All } & 527 & 74 & $1.3(0.77-2.31)$ \\
\hline & & & $P=0.29$ \\
\hline \multirow[t]{2}{*}{ ER+ } & 474 & 67 & $0.83(0.45-1.54$ \\
\hline & & & $P=0.56$ \\
\hline \multirow{2}{*}{$\begin{array}{l}\text { ER+ and age } \\
\geq 55 \mathrm{yrs}\end{array}$} & 328 & 51 & $0.91(0.44-1.91$ \\
\hline & & & $P=0.81$ \\
\hline \multirow{2}{*}{$\begin{array}{l}\text { ER+ and age } \\
<55 \text { yrs }\end{array}$} & 123 & 16 & $0.66(0.21-2.08$ \\
\hline & & & $P=0.48$ \\
\hline
\end{tabular}

$\begin{array}{lll}805 & 59 & 1.40(0.77-2.42) \\ & & P=0.28 \\ 695 & 40 & 1.90(0.96-3.77) \\ & & P=0.06 \\ 484 & 36 & 1.80(0.86-3.74) \\ & & P=0.12 \\ 208 & 4 & 3.65(0.31-42.97) \\ & & P=0.30\end{array}$

\begin{tabular}{|c|c|c|}
\hline \multirow[t]{2}{*}{804} & \multirow[t]{2}{*}{59} & $1.31(0.74-2.32)$ \\
\hline & & $P=0.35$ \\
\hline \multirow[t]{2}{*}{694} & 40 & $1.93(0.97-3.85)$ \\
\hline & & $P=0.06$ \\
\hline \multirow[t]{2}{*}{483} & 36 & $1.79(0.85-3.75)$ \\
\hline & & $P=0.12$ \\
\hline \multirow[t]{2}{*}{208} & 4 & $2.02(0.13-30.70)$ \\
\hline & & $P=0.61$ \\
\hline \multirow[t]{2}{*}{804} & 97 & $1.32(0.83-2.08)$ \\
\hline & & $P=0.24$ \\
\hline \multirow[t]{2}{*}{701} & 71 & $1.51(0.88-2.60)$ \\
\hline & & $P=0.13$ \\
\hline \multirow[t]{2}{*}{487} & 53 & $1.16(0.60-2.26)$ \\
\hline & & $P=0.66$ \\
\hline \multirow[t]{2}{*}{214} & 18 & $3.59(1.15-11.20)$ \\
\hline & & $P=0.03$ \\
\hline
\end{tabular}

\begin{tabular}{|c|c|c|}
\hline \multirow[t]{2}{*}{568} & 46 & $1.08(0.50-2.35)$ \\
\hline & & $P=0.83$ \\
\hline \multirow[t]{2}{*}{507} & 39 & $0.79(0.30-2.08)$ \\
\hline & & $P=0.64$ \\
\hline \multirow[t]{2}{*}{346} & 30 & $0.46(0.11-1.98)$ \\
\hline & & $P=0.30$ \\
\hline \multirow[t]{2}{*}{124} & 9 & $1.69(0.33-8.73)$ \\
\hline & & $P=0.53$ \\
\hline
\end{tabular}

$1.14(0.54-2.43)$

$P=0.73$

$0.77(0.29-2.01)$

$P=0.59$

$0.42(0.10-1.82)$

$P=0.25$

$1.60(0.35-7.46)$

$P=0.55$

\begin{tabular}{|c|c|c|}
\hline \multirow[t]{2}{*}{522} & 75 & $1.19(0.67-2.12)$ \\
\hline & & $P=0.54$ \\
\hline \multirow[t]{2}{*}{470} & 68 & $1.01(0.53-1.90)$ \\
\hline & & $P=0.99$ \\
\hline \multirow[t]{2}{*}{324} & 51 & $0.91(0.42-1.98)$ \\
\hline & & $P=0.82$ \\
\hline \multirow[t]{2}{*}{124} & 17 & $1.10(0.35-3.51)$ \\
\hline & & $P=0.87$ \\
\hline
\end{tabular}

$\begin{array}{lll}521 & 75 & 1.22(0.68-2.18) \\ & & P=0.50 \\ 469 & 68 & 1.05(0.56-2.00) \\ & & P=0.87 \\ 323 & 51 & \\ & & \\ & & P=97(0.44-2.10) \\ 124 & 17 & 1.24(0.36-4.20) \\ & & P=0.73\end{array}$


outcome in clinical BC. The significant associations between high intratumoral levels of CYP27A1 with aggressive breast tumor biological features seen in this study are consistent with previous reports [12,39] and align with the preclinical evidence supporting a pathogenic role of the $27 \mathrm{HC} / \mathrm{CYP} 27 \mathrm{~A} 1$ metabolic pathway in $\mathrm{BC}$ $[12,27,43]$.

For the first time and in population-based cohorts, we report a positive association between high CYP27A1 levels and increased risk for late lethal disease, especially among presumably postmenopausal patients presenting with ER+ BC. Prominently, the effect of CYP27A1 expression on prognosis was comparable in magnitude between the OS and BCSS. If high CYP27A1 expression translates into high $27 \mathrm{HC}$, this association with poor survival is thus consistent with the expected agonist activity of $27 \mathrm{HC}$ under the hypo-estrogenic physiological state prevalent in postmenopausal patients. Under these conditions, 27HC can still promote ER+ BC progression even under the pressure of endocrine therapies like aromatase inhibitor treatments since it can freely access the unaffected estrogen receptor driving the transcription of tumor growth-promoting genes. Adjusting for adjuvant treatment did not impact the association between CYP27A1 and survival suggesting that $27 \mathrm{HC}$ may indeed compromise survival and treatment efficacy in postmenopausal patients. We could, however, not evaluate if CYP27A1 modified the effects of specific types of endocrine therapies in MDCS because the data were not available but considering that over $90 \%$ of the patients were above 55 years old at time of diagnosis, it is likely that aromatase inhibitors may have been the treatment of choice for the patients diagnosed from 2009 and onwards when aromatase inhibitors became standard of care for postmenopausal patients. It has been reported that CYP27A1 activity can be inhibited in vitro by anastrozole but not by exemestane and letrozole [44] suggesting another level of complexity to the prognostic impact of CYP27A1 in postmenopausal BC that needs to be investigated.

The observation that the adverse prognostic impact of CYP27A1 expression was specifically prominent 5 years after diagnosis is remarkable since this corresponds to the time period when adjuvant endocrine therapy usually ends. Although the evidence currently indicates that extending AI-based treatment beyond 5 years does not reduce late recurrence risk in an unselected population of patients with ER+ BC [45-47], subset analyses indicated that patients with $\mathrm{ER}+/ \mathrm{PgR}$-positive, nodepositive disease might benefit from extended AI-based treatment.

Metastasis is the principal cause of BC-related death. CYP27A1 may also serve as a marker for selecting patients for extended adjuvant treatment trials in BC.
Recently, it was confirmed in the large randomized BIG 1-98 trial that the use of cholesterol-lowering drugs significantly improved survival in postmenopausal women regardless of whether the treatment was initiated before or during adjuvant endocrine therapy [20], but whether delaying the initiation of cholesterol-lowering drugs until after completing endocrine therapy will yield a meaningful survival benefit is still an open-ended question. These data suggest that cholesterol-lowering statins could be prescribed as maintenance therapy after completing adjuvant endocrine therapy, since it has been established that statins also decrease $27 \mathrm{HC}$ concentrations [39]. The adverse impact of high CYP27A1 expression on survival was however non-significant among postmenopausal patients with ER+ tumors only in the BC-blood cohort, despite the significant association with poor survival in the overall population. Some possible explanations for the null findings could be the relatively shorter followup; median follow-up of only 7.0 years in BC-blood relative to 10.8 years in MDCS, which may not have been sufficiently long to investigate late events. The more generous use of adjuvant systemic therapies in the BCblood resulted in fewer events to power the statistical analyses. Our previous study [39] evaluating the relationship between CYP27A1 mRNA expression and prognosis in $\mathrm{BC}$ did not also find a significant association between CYP27A1 with survival among patients $>50$ years, and similar to the BC-blood cohort, the median follow-up was only 7.2 years in that study [39]. In addition, the age cut-off of 50 years used in the previous study [39] may not be an optimal proxy for menopausal status. More investigations are therefore required to confirm this timedependent association between CYP27A1 expression and prognosis preferably in cohorts with reliable information regarding menopausal status and with extended follow-up.

The significantly higher RFS event rates associated with high intratumoral CYP27A1 expression in patients $<55$ years (pre- and perimenopausal) presenting with $\mathrm{ER}+$ tumors during the first 5 years after $\mathrm{BC}$ diagnosis in $\mathrm{BC}$-blood is intriguing since the logical expectation is that high $27 \mathrm{HC}$ should display antagonistic properties under estrogenic conditions and therefore be protective in premenopausal patients, a premise which was verified in our previous study [39] reporting a significant improved RFS and OS for younger patients ( $<50$ years old) presenting with high compared with low CYP27A1 mRNA in their tumors. Several studies have reported the benefit of suppressing ovarian function in premenopausal patients receiving endocrine therapies [48-50], and it is also well established that chemotherapy treatment can induce a postmenopausal physiological state in some premenopausal patients $[51,52]$. The more generous prescription of chemotherapy in $\mathrm{BC}$-blood and the 
higher likelihood that ovarian function suppressants may have been prescribed for patients in BC-blood given the more recent recruitment of patients into this cohort may to some extent explain the observed inverse association between high CYP27A1 and survival among the younger patients in this cohort. Additional differences in patients, tumor characteristics, and molecular assays used for measuring the expression of CYP27A1 between the studies (protein vs mRNA) may also have contributed to these divergent results. Unfortunately, with only $10 \%$ $(N=63)$ of the patients in MDCS under 55 years, it was impossible to perform any meaningful statistical evaluation among the younger patients, although a statistically non-significant trend showing a better survival for high CYP27A1 tumors was observed (data not shown). Though interesting, the limited number of cases and events included in this sub-group analysis in BC-blood warrants caution when interpreting these results. To better address this conundrum, an independent evaluation of CYP27A1 expression, both at the transcript and protein levels in the same patients in larger cohorts, is necessary to clarify the association between CYP27A1, menopausal status, and $\mathrm{BC}$ prognosis.

Although this observational study is based on two large population-based $\mathrm{BC}$ cohorts with clinical and tumor pathological data available for many conventional prognostic markers in $\mathrm{BC}$, the results as presented may have been impacted by other important factors not mentioned above. Incorporation of other obesity-related factors besides body size measurements, lipid profiles in the tumor microenvironment and in the circulation, and complete treatment information into multivariable models in cohorts with extensive follow-up data will improve our appreciation of factors that influence endocrine therapy efficacy and the role of cholesterol metabolism in late recurrent disease pathobiology in postmenopausal patients.

\section{Conclusion}

Except for serum cholesterol measurements, only a few clinical studies have directly addressed the prognostic role of genes associated with cholesterol metabolism in $\mathrm{BC}[12,18,30,39]$. A simple measurement of the serum cholesterol level cannot explain the molecular mechanism(s) driving tumor progression. Dysregulation of genes regulating cholesterol metabolism in the tumor might add value for prognostication and treatment prediction $[15,18]$. Here, we present a novel biomarker of late lethal disease in postmenopausal $\mathrm{ER}+\mathrm{BC}$, which is directly involved in cholesterol metabolism. Of relevance, these results provides indirect evidence that explains the associations between high cholesterol, obesity, and postmenopausal BC onset and progression seen in epidemiological studies and supports testing pharmacological drugs that decrease cholesterol metabolism and block CYP27A1 activity in postmenopausal patients with $\mathrm{ER}+\mathrm{BC}$.

\section{Supplementary information}

Supplementary information accompanies this paper at https://doi.org/10. 1186/s13058-020-01347-x.

Additional file 1:. Supplementary table 1: Baseline patient and tumor characteristics in evaluable and non-evaluable patients.

Additional file 2:. Supplementary table 2: Associations between CYP27A1 expression and anthropometric factors in the BC-Blood cohort.

Additional file 3:. Supplementary table 3: Adjusted hazard ratios $(95 \% \mathrm{Cl})$ for overall survival and breast cancer-specific survival by tumor CYP27A1 expression in MDCS cohort over the full follow up period.

Additional file 4:. Supplementary table 4: Adjusted hazard ratios (95\% Cl) for overall survival and recurrence-free survival by tumor CYP27A1 expression in BC-blood cohort over the full follow up period.

\section{Abbreviations}

27HC: 27-Hydroxycholesterol; ER+: Estrogen receptor-positive; BC: Breast cancer; CYP27A1: Cytochrome P450 family 27 subfamily A member 1; HR: Hazard ratio; Cl: Confidence interval; OS: Overall survival; BCSS: Breast cancer-specific survival; RFS: Recurrence-free survival; MDCS: Malmö Diet and Cancer Study; BC-blood: Breast Cancer blood study;

IHC: Immunohistochemistry; FFPE: Formalin-fixed paraffin-embedded; TMA: Tissue microarrays; OR: Odds ratio; IQR: Interquartile range;

PgR: Progesterone receptor; Al: Aromatase inhibitor

\section{Acknowledgements \\ The authors express their profound gratitude to Kristina Lövgren for performing the CYP27A1 IHC staining, Pär-Ola Bendahl for statistical consultation, Anna Hwasser for database administration in the MDCS, and Linda Ågren, Helén Thell, Jessica Åkesson, Anette Ahlin Gullers, Monika Eberhard Mészaros, Maj-Britt Hedenblad, Karin Henriksson, Anette Möller, Erika Bågeman, Maria Henningson, and Maria Hjertberg for their contribu- tions in patient recruitment and data entry for the BC-blood study.}

\section{Authors' contributions}

SK, HJ, and SB conceived and designed the study. KJ supervised the pathological evaluation. BN performed the TMA construction and IHC staining. SK, MI, and TS assessed the CYP27A1 expression. KE, HT, MYR, and HJ provided technical and administrative support (i.e., reporting or organizing data, construction of database). $\mathrm{Kl}, \mathrm{KJ}, \mathrm{SB}$, and $\mathrm{HJ}$ assisted in acquisition of data (patient management, provided facilities, etc.). SK, MI, HJ, and SB analyzed the data and drafted the manuscript. All authors read and approved the manuscript.

\section{Funding}

This work was supported by grants from The Swedish Cancer Society, the Mrs. Berta Kamprad Foundation, the Swedish Research Council, the Swedish Cancer Foundation, the Gunnar Nilsson Cancer Foundation, the Royal Physiographic Society of Lund, the Medical Faculty at Lund University, the South Swedish Health Care Region (Region Skåne ALF), and the Lund Hospital Fund. The funding agencies played no role in the design of the study, the collection, analysis, and interpretation of the data, or preparation of the manuscript for publication. Open Access funding provided by Lund University.

\section{Availability of data and materials}

The data that support the findings from the Malmo Diet and Cancer cohort of this study are available on reasonable request from the corresponding authors (SK) and Signe Borgquist (SB).

\section{Ethics approval and consent to participate}

All patients provided a written informed consent to participate in both original studies. This current study is covered by ethical approvals from the Lund University ethics committee: MDCS; Dnr 472/2007 and BC-blood; Dnr 
LU75-02, LU37-08, LU658-09, LU58-12, LU379-12, LU227-13, LU277-15, and LU458-15, requiring no further amendments.

\section{Consent for publication}

Not applicable.

\section{Competing interests}

The authors declare that they have no competing interests.

\section{Author details}

'Department of Clinical Sciences Lund, Division of Oncology, Lund University, Barngatan 4, SE-221 85 Lund, Sweden. ${ }^{2}$ Department of Clinical Sciences Lund, Division of Oncology and Therapeutic Pathology, Lund University, Lund, Sweden. ${ }^{3}$ Department of Reconstructive Plastic Surgery, Skåne University Hospital, Malmö, Sweden. ${ }^{4}$ Department of Clinical Sciences Lund, Division of Surgery, Lund University, Lund, Sweden. ${ }^{5}$ Department of Surgery, Central Hospital, Kristianstad, Sweden. ${ }^{6}$ Department of Oncology, Aarhus University Hospital, Aarhus University, Aarhus, Denmark.

\section{Received: 24 March 2020 Accepted: 1 October 2020}

\section{Published online: 11 November 2020}

\section{References}

1. DeSantis CE, Ma J, Gaudet MM, Newman LA, Miller KD, Goding Sauer A, Jemal A, Siegel RL. Breast cancer statistics, 2019. CA Cancer J Clin. 2019; 69(6):438-51.

2. Hanker $A B$, Sudhan $D R$, Arteaga CL. Overcoming endocrine resistance in breast cancer. Cancer Cell. 2020;37(4):496-513.

3. Bray F, Ferlay J, Soerjomataram I, Siegel RL, Torre LA, Jemal A. Global cancer statistics 2018: GLOBOCAN estimates of incidence and mortality worldwide for 36 cancers in 185 countries. CA Cancer J Clin. 2018;68(6):394-424.

4. Vrieling A, Buck K, Kaaks R, Chang-Claude J. Adult weight gain in relation to breast cancer risk by estrogen and progesterone receptor status: a metaanalysis. Breast Cancer Res Treat. 2010;123(3):641-9.

5. Ewertz $M$, Jensen MB, Gunnarsdottir KA, Hojris I, Jakobsen EH, Nielsen D, Stenbygaard LE, Tange UB, Cold S. Effect of obesity on prognosis after earlystage breast cancer. J Clin Oncol. 2011;29(1):25-31.

6. Jiralerspong S, Goodwin PJ. Obesity and breast cancer prognosis: evidence, challenges, and opportunities. J Clin Oncol. 2016;34(35):4203-16.

7. Jiralerspong S, Kim ES, Dong W, Feng L, Hortobagyi GN, Giordano SH. Obesity, diabetes, and survival outcomes in a large cohort of early-stage breast cancer patients. Ann Oncol. 2013;24(10):2506-14.

8. Anderson GL, Manson J, Wallace R, Lund B, Hall D, Davis S, Shumaker S, Wang CY, Stein E, Prentice RL. Implementation of the Women's Health Initiative study design. Ann Epidemiol. 2003;13(9 Suppl):S5-17.

9. Hu J, La Vecchia C, de Groh M, Negri E, Morrison H, Mery L. Canadian Cancer Registries Epidemiology Research G: dietary cholesterol intake and cancer. Ann Oncol. 2012;23(2):491-500.

10. Danilo C, Frank PG. Cholesterol and breast cancer development. Curr Opin Pharmacol. 2012;12(6):677-82.

11. Bahl M, Ennis M, Tannock IF, Hux JE, Pritchard Kl, Koo J, Goodwin PJ. Serum lipids and outcome of early-stage breast cancer: results of a prospective cohort study. Breast Cancer Res Treat. 2005;94(2):135-44.

12. Nelson ER, Wardell SE, Jasper JS, Park S, Suchindran S, Howe MK, Carver NJ, Pillai RV, Sullivan PM, Sondhi V, et al. 27-Hydroxycholesterol links hypercholesterolemia and breast cancer pathophysiology. Science (New York, NY). 2013;342(6162):1094-8.

13. Du Q, Wang Q, Fan H, Wang J, Liu X, Wang H, Wang Y, Hu R. Dietary cholesterol promotes AOM-induced colorectal cancer through activating the NLRP3 inflammasome. Biochem Pharmacol. 2016;105:42-54.

14. Moon H, Ruelcke JE, Choi E, Sharpe LJ, Nassar ZD, Bielefeldt-Ohmann H, Parat MO, Shah A, Francois M, Inder KL, et al. Diet-induced hypercholesterolemia promotes androgen-independent prostate cancer metastasis via IQGAP1 and caveolin-1. Oncotarget. 2015;6(10):7438-53.

15. Kimbung $S$, Lettiero B, Feldt M, Bosch A, Borgquist S. High expression of cholesterol biosynthesis genes is associated with resistance to statin treatment and inferior survival in breast cancer. Oncotarget. 2016;7(37): 59640-51.

16. Kolanjiappan K, Ramachandran CR, Manoharan S. Biochemical changes in tumor tissues of oral cancer patients. Clin Biochem. 2003;36(1):61-5.
17. Ding $X$, Zhang W, Li S, Yang H. The role of cholesterol metabolism in cancer. Am J Cancer Res. 2019;9(2):219-27.

18. Clendening JW, Pandyra A, Boutros PC, El Ghamrasni S, Khosravi F, Trentin GA, Martirosyan A, Hakem A, Hakem R, Jurisica I, et al. Dysregulation of the mevalonate pathway promotes transformation. Proc Natl Acad Sci U S A. 2010;107(34):15051-6.

19. Thurnher M, Nussbaumer O, Gruenbacher G. Novel aspects of mevalonate pathway inhibitors as antitumor agents. Clin Cancer Res. 2012;18(13):3524-31.

20. Borgquist S, Giobbie-Hurder A, Ahern TP, Garber JE, Colleoni M, Lang I, Debled M, Ejlertsen B, von Moos R, Smith I, et al. Cholesterol, cholesterollowering medication use, and breast cancer outcome in the BIG 1-98 study. J Clin Oncol. 2017;35(11):1179-88.

21. Ahern TP, Pedersen L, Tarp M, Cronin-Fenton DP, Garne JP, Silliman RA, Sørensen HT, Lash TL. Statin prescriptions and breast cancer recurrence risk: a Danish nationwide prospective cohort study. J Natl Cancer Inst. 2011; 103(19):1461-8.

22. Ahern TP, Lash TL, Damkier P, Christiansen PM, Cronin-Fenton DP. Statins and breast cancer prognosis: evidence and opportunities. Lancet Oncol. 2014;15(10):e461-8.

23. Nielsen SF, Nordestgaard BG, Bojesen SE. Statin use and reduced cancerrelated mortality. N Engl J Med. 2012;367(19):1792-802.

24. DuSell CD, Umetani M, Shaul PW, Mangelsdorf DJ, McDonnell DP. 27hydroxycholesterol is an endogenous selective estrogen receptor modulator. Mol Endocrinol. 2008;22(1):65-77.

25. Umetani M, Domoto H, Gormley AK, Yuhanna IS, Cummins CL, Javitt NB, Korach KS, Shaul PW, Mangelsdorf DJ. 27-Hydroxycholesterol is an endogenous SERM that inhibits the cardiovascular effects of estrogen. Nat Med. 2007;13(10):1185-92.

26. He S, Nelson ER. 27-Hydroxycholesterol, an endogenous selective estrogen receptor modulator. Maturitas. 2017;104:29-35.

27. Baek AE, YU YA, He S, Wardell SE, Chang CY, Kwon S, Pillai RV, McDowell HB, Thompson JW, Dubois LG, et al. The cholesterol metabolite 27 hydroxycholesterol facilitates breast cancer metastasis through its actions on immune cells. Nat Commun. 2017:8(1):864.

28. Berglund G, Elmstahl S, Janzon L, Larsson SA. The Malmo Diet and Cancer Study. Design and feasibility. J Intern Med. 1993;233(1):45-51.

29. Manjer J, Carlsson S, Elmstahl S, Gullberg B, Janzon L, Lindstrom M, Mattisson I, Berglund G. The Malmo Diet and Cancer Study: representativity, cancer incidence and mortality in participants and non-participants. Eur J Cancer Prev. 2001;10(6):489-99.

30. Borgquist S, Djerbi S, Ponten F, Anagnostaki L, Goldman M, Gaber A, Manjer J, Landberg G, Jirstrom K. HMG-CoA reductase expression in breast cancer is associated with a less aggressive phenotype and influenced by anthropometric factors. Int J Cancer. 2008;123(5):1146-53.

31. Elebro K, Bendahl PO, Jernstrom H, Borgquist S. Androgen receptor expression and breast cancer mortality in a population-based prospective cohort. Breast Cancer Res Treat. 2017;165(3):645-57.

32. Markkula A, Bromee A, Henningson M, Hietala M, Ringberg A, Ingvar C, Rose C, Jernstrom H. Given breast cancer, does breast size matter? Data from a prospective breast cancer cohort. Cancer Causes Control. 2012;23(8):1307-16.

33. Markkula A, Hietala M, Henningson M, Ingvar C, Rose C, Jernstrom H. Clinical profiles predict early nonadherence to adjuvant endocrine treatment in a prospective breast cancer cohort. Cancer Prev Res (Phila). 2012;5(5):735-45.

34. Markkula A, Simonsson M, Rosendahl AH, Gaber A, Ingvar C, Rose C, Jernstrom $\mathrm{H}$. Impact of COX2 genotype, ER status and body constitution on risk of early events in different treatment groups of breast cancer patients. Int J Cancer. 2014;135(8):1898-910.

35. Simonsson M, Markkula A, Bendahl PO, Rose C, Ingvar C, Jernstrom H. Preand postoperative alcohol consumption in breast cancer patients: impact on early events. SpringerPlus. 2014;3:261.

36. Gustbee E, Tryggvadottir H, Markkula A, Simonsson M, Nodin B, Jirstrom K, Rose C, Ingvar C, Borgquist S, Jernstrom H. Tumor-specific expression of HMG-CoA reductase in a population-based cohort of breast cancer patients. BMC Clin Pathol. 2015;15:8

37. Tryggvadottir H, Huzell L, Gustbee E, Simonsson M, Markkula A, Jirstrom K, Rose $C_{\text {, Ingvar }}$, Borgquist $\mathrm{S}$, Jernstrom $\mathrm{H}$. Interactions between $\mathrm{ABCB} 1$ genotype and preoperative statin use impact clinical outcomes among breast cancer patients. Front Oncol. 2018;8:428.

38. Persson M, Simonsson M, Markkula A, Rose $C$, Ingvar $C$, Jernstrom $H$. Impacts of smoking on endocrine treatment response in a prospective breast cancer cohort. Br J Cancer. 2016;115(3):382-90. 
39. Kimbung S, Chang CY, Bendahl PO, Dubois L, Thompson JW, McDonnell DP, Borgquist S. Impact of 27-hydroxylase (CYP27A1) and 27-hydroxycholesterol in breast cancer. Endocr Relat Cancer. 2017;24(7):339-49.

40. McShane LM, Altman DG, Sauerbrei W, Taube SE, Gion M, Clark GM. Statistics subcommittee of the NCIEWGoCD: REporting recommendations for tumor MARKer prognostic studies (REMARK). Nat Clin Pract Urol. 2005; 2(8):416-22.

41. Dupont WD, Plummer WD Jr. Power and sample size calculations. A review and computer program. Control Clin Trials. 1990;11(2):116-28.

42. Cardoso F, Kyriakides S, Ohno S, Penault-Llorca F, Poortmans P, Rubio IT, Zackrisson S, Senkus E, Committee EG. Early breast cancer: ESMO Clinical Practice Guidelines for diagnosis, treatment and follow-updagger. Ann Oncol. 2019;30(8):1194-220.

43. Wu Q, Ishikawa T, Sirianni R, Tang H, McDonald JG, Yuhanna IS, Thompson B, Girard L, Mineo C, Brekken RA, et al. 27-Hydroxycholesterol promotes cellautonomous, ER-positive breast cancer growth. Cell Rep. 2013;5(3):637-45.

44. Mast N, Lin JB, Pikuleva IA. Marketed drugs can inhibit cytochrome P450 $27 \mathrm{~A} 1$, a potential new target for breast cancer adjuvant therapy. Mol Pharmacol. 2015;88(3):428-36.

45. Blok EJ, Kroep JR, Meershoek-Klein Kranenbarg E, Duijm-de Carpentier M, Putter H, van den Bosch J, Maartense E, van Leeuwen-Stok AE, Liefers GJ, Nortier JWR et al: Optimal duration of extended adjuvant endocrine therapy for early breast cancer; results of the IDEAL Trial (BOOG 2006-05). J Natl Cancer Inst. 2018;1 10(1):40-8.

46. Colleoni M, Luo W, Karlsson P, Chirgwin J, Aebi S, Jerusalem G, Neven P, Hitre $E_{1}$ Graas MP, Simoncini E, et al. Extended adjuvant intermittent letrozole versus continuous letrozole in postmenopausal women with breast cancer (SOLE): a multicentre, open-label, randomised, phase 3 trial. Lancet Oncol. 2018;19(1):127-38.

47. Goldvaser H, Barnes TA, Seruga B, Cescon DW, Ocana A, Ribnikar D, Amir E: Toxicity of Extended Adjuvant Therapy With Aromatase Inhibitors in Early Breast Cancer: A Systematic Review and Meta-analysis. J Natl Cancer Inst. 2018;110(1):31-9.

48. Francis PA, Regan MM, Fleming GF, Lang I, Ciruelos E, Bellet M, Bonnefoi HR, Climent MA, Da Prada GA, Burstein HJ, et al. Adjuvant ovarian suppression in premenopausal breast cancer. N Engl J Med. 2015;372(5):436-46.

49. Pagani O, Regan MM, Walley BA, Fleming GF, Colleoni M, Lang I, Gomez HL, Tondini C, Burstein HJ, Perez EA, et al. Adjuvant exemestane with ovarian suppression in premenopausal breast cancer. N Engl J Med. 2014;371(2): 107-18.

50. Kim HA, Lee JW, Nam SJ, Park BW, Im SA, Lee ES, Jung YS, Yoon JH, Kang SS, Lee SJ, et al. Adding ovarian suppression to tamoxifen for premenopausal breast cancer: a randomized phase III trial. J Clin Oncol. 2020;38(5):434-43.

51. Pagani O, O'Neill A, Castiglione M, Gelber RD, Goldhirsch A, Rudenstam CM, Lindtner J, Collins J, Crivellari D, Coates A, et al. Prognostic impact of amenorrhoea after adjuvant chemotherapy in premenopausal breast cancer patients with axillary node involvement: results of the International Breast Cancer Study Group (IBCSG) Trial VI. Eur J Cancer. 1998;34(5):632-40.

52. International Breast Cancer Study G, Colleoni M, Gelber S, Goldhirsch A, Aebi S, Castiglione-Gertsch M, Price KN, Coates AS, Gelber RD. Tamoxifen after adjuvant chemotherapy for premenopausal women with lymph nodepositive breast cancer: International Breast Cancer Study Group Trial 13-93. J Clin Oncol. 2006;24(9):1332-41.

\section{Publisher's Note}

Springer Nature remains neutral with regard to jurisdictional claims in published maps and institutional affiliations.

Ready to submit your research? Choose BMC and benefit from:
- fast, convenient online submission
- thorough peer review by experienced researchers in your field
- rapid publication on acceptance
- support for research data, including large and complex data types
- gold Open Access which fosters wider collaboration and increased citations
- maximum visibility for your research: over 100M website views per year
At BMC, research is always in progress.
Learn more biomedcentral.com/submissions

